\title{
MACHADO: DO DISCURSO ROMÂNTICO DA NACIONALIDADE À CRÍTICA RADICAL DA NAÇÃO
}

\author{
João Hernesto Weber (ensaísta convidado) \\ Universidade Federal de Santa Catarina \\ Florianópolis, SC, Brasil
}

\begin{abstract}
Resumo: O artigo se detém, inicialmente, numa leitura da camada aparente de "Instinto de nacionalidade", destacando sua vinculação com as teses românticas sobre o sentido de "nação" e "literatura nacional", insistindo Machado na literatura indigenista, na cor local, na feição americana como paradigma para detectar a nacionalidade do texto literário. Em outra camada de leitura, apontamse as reticências, as negações, o estilo carregado de adversativas que permeiam o texto, a ponto de Machado vir a negar as teses românticas em sua exclusividade, para, finalmente, abrir o leque do que poderia significar "literatura nacional": tudo é matéria de poesia. Na sequência, analisa-se a formação do Machado ficcionista, quando viria a exercitar o que já se encontrava, em tese, no "Instinto". Por fim, lançam-se algumas questões sobre a importância do ensaio para a crítica e a historiografia literária locais.
\end{abstract}

Palavras-chave: "Instinto de nacionalidade"; literatura nacional; nacionalidade; Romantismo.

\section{Machado: from the romantic discourse on nationality to the radical criticism on the nation}

\begin{abstract}
Initially, the article engages in a reading of the most apparent level of "Instinto de nacionalidade", pointing out its connection with romantic theories about the meaning of "nation" and "national literature," a level where Machado confronts indigenist literature, local color, and American customs as a paradigm to define the nationality of a literary text. On another level, the essay points out the hesitations, negations and oppositions that inform the text, suggesting Machado's denial of romantic theories as an exclusive model, in order finally to suggest a more open notion of what would constitute "national literature": it is all a matter of poetry. And then the article analyzes the development of Machado as a writer of fiction, when he would come to exercise the theses developed in "Instinto." Finally, this text poses some questions about the importance of the essay for local criticism and literary history.
\end{abstract}

Keywords: "Instinto de nacionalidade"; national literature; nationality; Romanticism. 
A atuação crítica e reflexiva de Machado de Assis em torno da nacionalidade da literatura brasileira e, por consequência, da existência da própria nação - pois que a existência de uma literatura nacional, na visão corriqueira da historiografia literária local, de fundo romântico, corroboraria a existência da própria nação - data do início de sua atividade jornalística. Quando o autor contava ainda menos de vinte anos de idade, escrevia, já, "O passado, o presente e o futuro da literatura", espécie de rascunho daquele que viria a ser o seu mais conhecido ensaio crítico, o "Instinto de nacionalidade". Nele, rastreava a tradição literária local, criticava Gonzaga pelo seu compromisso com a Arcádia, e louvava Basílio da Gama, que elaborara, a seu ver, poesia não nacional, mas indígena, diferenciada, ainda assim, ou por isso mesmo, da portuguesa. Passa pelos Andradas e outros, e pelas duas revoluções necessárias: a do Sete de Setembro e a da literatura, para a qual não haveria "gritos de Ipiranga". Trata, no ensaio, do romance, da poesia e do drama, afirmando a pobreza do último, concentrando a sua crítica no problema da proliferação das traduções do francês, inibidoras, a seu ver, da produção local, para o que propõe, como solução, o estabelecimento de uma espécie de "reserva de mercado" para o drama local.

Em 30 de outubro de 1859, aos vinte anos de idade, portanto, vamos, entre outras intervenções, encontrá-lo a publicar uma crônica em $O$ Espelho, intitulada "O folhetinista". A sua conclusão sobre a condição do folhetinista no Brasil é indicativa das "aflições estéticas", e também políticas, por que já passava o jovem Machado, aflições que norteariam a sua atividade crítica e literária posterior:

Força é dizê-lo: a cor nacional, em raríssimas exceções, tem tomado o folhetinista entre nós. Escrever folhetim e ficar brasileiro é na verdade difícil. Entretanto, como todas as dificuldades se aplanam, ele podia bem tomar mais cor local, mais feição americana. Faria assim menos mal à independência do espírito nacional, tão preso a essas imitações, a esses arremedos, a esse suicídio de originalidade e iniciativa. 
Nesse sentido, pode-se afirmar que aos dezenove, vinte anos, Machado já se preocupava com a adaptação de modelos europeus às circunstâncias locais. Referia-se, na passagem acima, ao folhetim-crônica, tarefa do jornalista que, ao pé de página do jornal, comentava a vida social, imitando o folhetim francês. Machado, também folhetinistacronista, criticava, portanto, já àquele tempo, a adesão, pura e simples, à imitação dos folhetins franceses. E o fazia de forma crítica, ao desenhar tipos como o fanqueiro e o parasita literário, como se pode ler nas crônicas de $O$ Espelho.

"O passado, o presente e o futuro da literatura" e "O folhetinista", aqui citados, são textos bastante marcados pelos índices de nacionalidade predicados pelas teses românticas, como facilmente se percebe quando Machado reivindica, num, a primazia de Basílio da Gama sobre Gonzaga e, noutro, maior presença de "cor local" e mais "feição americana". É um marco, ainda assim, para o que Machado afirmaria no seu conhecido "Instinto de nacionalidade", de 1873, em que estabelece, num texto em princípio despretensioso, para ser publicado em Português numa revista de Nova Iorque, a sua visão sobre a literatura nacional e, por extensão, sobre a própria nação.

No "Instinto de nacionalidade", Machado parte da constatação de que a literatura brasileira expressa um certo "instinto de nacionalidade". Afirma, também, que "todas as formas literárias do pensamento buscam vestir-se com as cores do país". Machado acompanha, nesse sentido, a tradição romântica, que passa, em termos críticos, por Ferdinand Denis, Gonçalves de Magalhães, Joaquim Norberto e Santiago Nunes Ribeiro, entre outros. Tanto que, a seguir, ele estabelece uma linha de continuidade na literatura brasileira que toma por base, justamente, a expressão das "cores do país". Essa linha de continuidade teria Gonçalves Dias e Araújo Porto Alegre ao centro; projetar-se-ia ao passado nas obras de Basílio da Gama e Santa Rita Durão; e expandir-se-ia ao futuro através daquela geração que "agora madruga". A existência dessa tradição, na visão de Machado, seria um ganho, e apontaria para um futuro promissor: "Interrogando a vida brasileira e a natureza americana, prosadores e poetas acharão ali farto manancial de inspiração e irão dando fisionomia própria ao pensamento nacional". 
Machado volta-se também à recepção das obras: o público, alicerçado nessa tradição, preferiria Basílio da Gama a Gonzaga, por exemplo. O público, em última instância, ao ver de Machado, teria dado preferência à tradição romântica que buscava construir uma genealogia positiva para a incipiente "nação".

Machado, na sequência, retorna a Gonçalves Dias. Retoma, na verdade, a linhagem que se estende de Santa Rita Durão a Gonçalves Dias. Em seguida, Machado afirma, de outra parte, que os escritores, entendendo não estar no indígena todo o patrimônio da literatura brasileira, estariam buscando outras fontes de inspiração: o passado histórico, cenas do presente, a que aduz, novamente, a cor local da "natureza americana".

Esse o resumo da primeira parte do ensaio de Machado, quando se o lê assim como o fizemos: o horizonte de Machado, em 1873, ano da publicação do ensaio, ainda é aquele desenhado pelo Romantismo. É forte a presença dos índices de nacionalidade literária românticos, como a cor local, o indigenismo, a natureza americana, o que lhe permite construir e rastrear uma das linhas de continuidade da literatura brasileira, a se estender de Santa Rita Durão a Gonçalves Dias, como afirmávamos.

Machado insiste nisso, como se pode perceber pelas assertivas, mais minhas que dele, acima citadas; é o indígena, é a cor local, é a natureza americana, é a sobrevalorização da tradição - de uma tradição, na verdade - que toma o indianismo por vetor. Nesse sentido, pela insistência, o "Instinto", à primeira vista, parece um texto insosso, que chega a aborrecer, por bater sempre na mesma tecla, amparado na historiografia literária do Romantismo. Lendo-se o texto nessa ótica, como acima o fizemos, percebe-se o quanto Machado devia a essa tradição e o quanto a reproduzia, amparando-se na tradição que vem de Ferdinand Denis, Gonçalves de Magalhães, Joaquim Norberto e Santiago Nunes Ribeiro, em seus intentos de construírem uma referência para o que devesse ser entendido como "literatura nacional". É texto que participa do clima de ufanismo pela constituição de uma pátria nos trópicos, livre dos entraves coloniais, principalmente em relação à metrópole. Com um adendo: o texto é posterior aos textos críticos "fundacionais", o que lhe imprime um certo travo de sensaboria, de certa platitude anacrônica de elogio ao imaginário do Império, assentado, justamente, do ponto de vista simbólico, nos índices de nacionalidade 
tradicionais. Não entrevê, em suma, as contradições que, àquela altura, começavam a corroer o Império, deixando de tomar em consideração, por exemplo, a escravidão, o papel do negro na fundação da "nação", a pobreza que grassava entre os homens livres pobres, as instituições políticas já combalidas, os paradoxos impostos pelas "ideias fora do lugar", bandeiras já deflagradas e agitadas pelas correntes críticas que pretendiam se alçar ao poder, via republicanismo e federalismo, a partir dos anos setenta.

\section{II}

Evidentemente, forcei um pouco a mão nas afirmações acima. É que o artigo de Machado é tudo isso, mas não é somente isso. Pois Machado, em frases adversativas lapidares, sucintas, intercaladas no texto, afirma que preferir Basílio da Gama ou Santa Rita Durão a Gonzaga seria "um erro". Diz ele que valorizar a obra de Basílio da Gama ou de Santa Rita Durão em detrimento dos neoclássicos seria empregar um "critério injusto": embora neoclássicos, não haveria por que censurá-los por "não haverem trabalhado para a independência literária, quando a independência política jazia ainda no ventre do futuro, e mais que tudo, quando entre a metrópole e a colônia criara a história a homogeneidade das tradições, dos costumes e da educação." Além disso, era preciso ver, diz Machado, que Basílio da Gama e Durão pretendiam, muito mais do que tornar independente a literatura brasileira, ostentar certa cor local.

Percebe-se, aqui, o primeiro salto machadiano: enquanto recupera uma linha de força na literatura brasileira, que exclui os neoclássicos como Gonzaga, ele, ao mesmo tempo, em espécie de subtexto, que mina o texto aparente, a desautoriza, porque a exclusão seria equivocada, fruto de um anacronismo: não se deve, em suma, exigir de um tempo passado aquilo que ele não nos pode dar... Na sequência, ele contrapõe os argumentos daqueles que buscam contestar a tradição romântica local, por afirmarem não haver relação da poesia brasileira com a "raça extinta". Machado, assim como se opusera à exclusão dos árcades, mesmo em desconforto com seus idílios pastoris, contesta, também, a exclusão do indianismo: tudo, para ele, é matéria de poesia: 
É certo que a civilização brasileira não está ligada ao elemento indiano, nem dele recebeu influxo algum; e isto basta para não ir buscar entre as tribos vencidas os títulos da nossa personalidade literária. Mas se isto é verdade, não é menos certo que tudo é matéria de poesia, uma vez que traga as condições do belo ou os elementos de que ele se compõe. Os que, segundo o Sr. Varnhagen, negam tudo aos primeiros povos deste país, esses podem logicamente excluí-los da poesia contemporânea. Parece-me, entretanto, que, depois das memórias que a este respeito escreveram os Srs. Magalhães e Gonçalves Dias, não é lícito arredar o elemento indiano da nossa aplicação intelectual. Erro seria constituí-lo um exclusivo patrimônio da literatura brasileira; erro igual fora certamente a sua absoluta exclusão.

É importante observar, a partir dessa citação: Machado discorda das críticas ao indianismo, por tenderem à exclusão do "elemento indiano" como matéria de poesia; concorda com elas, de outra parte, na medida em que ele rejeita o indianismo como matéria exclusiva de poesia.

Evidentemente, esses escritores que rejeitam o indianismo, ao incorporarem outros temas à literatura dita "nacional", estariam "abrindo o leque" do que significava fazer literatura brasileira. Ainda assim, haveria aqui uma "opinião errônea", a de que só se deva atribuir espírito nacional às obras que tratam de assunto local:

Não há dúvida que uma literatura, sobretudo uma literatura nascente, deve principalmente alimentar-se dos assuntos que lhe oferece a sua região; mas não estabeleçamos doutrinas tão absolutas que a empobreçam. O que se deve exigir do escritor antes de tudo, é certo sentimento íntimo, que o torne homem do seu tempo e do seu país, ainda quando trate de assuntos remotos no tempo e no espaço.

A citação tem um sentido evidente: Machado "estoura" com a tradição do indianismo, ao mesmo tempo em que rompe com aqueles que, mesmo alargando o leque do que pudesse significar "literatura nacional", a encarceravam nos limites do local. 
Nesse sentido é que se pode afirmar que, se o horizonte discursivo de Machado, no "Instinto", ainda é o do Romantismo, esse discurso não é, pura e simplesmente, assimilado como tal: ao mesmo tempo em que Machado reconstitui o discurso romântico, ele o destrói em sua exclusividade, com sua peculiar dialética discursiva, que aponta o "erro" das opiniões excludentes. São frases, dizia, lapidares, assentadas no "seria um erro", no "critério injusto", deixando vir à tona, a cada passo, o outro texto que se esconde por detrás do texto que reafirma a tradição.

Acompanhe-se a lógica argumentativa de Machado. Ele utiliza uma tática discursiva que afirma algo para, a seguir, negá-lo, sem excluir o negado. Se Machado identifica o "instinto de nacionalidade" com as "cores do país", ele, em seguida, questiona a exclusividade desse critério; ao analisar o indianismo e a reação ao indianismo, nega o exclusivismo do indianismo, sem rejeitá-lo, no entanto, como uma das fontes de inspiração literária; se concorda com que os "costumes civilizados" e a natureza do país devam ser contemplados, nega, de outra parte, também o exclusivismo dessa noção, por considerá-la caudatária da concepção que somente identifica a presença do espírito nacional em obras que tratam de assunto local. Machado, assim agindo, revive e revigora as concepções dominantes em sua época, para, sempre, a seguir, desconstituí-las como tal, isto é, em sua exclusividade.

Em oposição, propõe a sua chave: a existência necessária de um certo "sentimento íntimo" que torne o escritor "um homem de seu tempo e de seu país, ainda quando trate de assuntos remotos no tempo e no espaço".

Essa lógica argumentativa, assim como a expusemos, leva, necessariamente, à transformação da tradição romântica: se Machado realiza uma síntese do pensamento romântico sobre a literatura brasileira, ele, ao mesmo tempo, coloca o Romantismo sob suspeição, através do constante afirmar e negar, sem excluir o negado. Ele, na verdade, desautoriza a exclusividade da concepção romântica. E se a literatura, à época em que escrevia o ensaio, abria o seu leque para assuntos como o sertanismo e a temática urbana, Machado abre ainda mais o leque: tudo é assunto para a literatura "nacional", desde que se 
preserve o "sentimento íntimo", ou seja, se preserve, diríamos hoje, o lugar de onde se observa o mundo.

\section{III}

Isso, quanto à primeira parte do ensaio, enquadrando-o diante do romantismo corlocalista. Cumpre, ainda, lançar um rápido olhar à segunda parte do texto, em que aborda os diferentes gêneros literários e sua expressão no País. Depois de lamentar a insuficiência da crítica, lacuna que ele próprio buscaria preencher, através de seus ensaios críticos, Machado tece uma breve apreciação a respeito do romance, a forma "mais apreciada" no Brasil, diante da inexistência, diz ele, de estudos especializados, como a filosofia, a linguística, os estudos de crítica histórica, numa percepção, por sinal, extremamente avançada para a época sobre o papel fundamental exercido pela literatura no Brasil como meio de indagação sobre a construção da formação nacional — vale lembrar, a propósito, que os estudos, ainda assim de cunho ensaístico-literário, sobre a formação nacional brasileira iniciam-se somente nos anos trinta do século passado, com Gilberto Freyre, Sérgio Buarque de Holanda e Caio Prado Júnior, por exemplo. Investigando, portanto, essa forma "mais apreciada" pelo público, dedica-se a mapear a temática do romance brasileiro existente à sua época:

Aqui o romance, como tive ocasião de dizer, busca sempre a cor local. A substância, não menos que os acessórios, reproduzem geralmente a vida brasileira em seus diferentes aspectos e situações. Naturalmente os costumes do interior são os que conservam melhor a tradição nacional; os da capital do país, e em parte, os de algumas cidades, muito mais chegados à influência europeia, trazem já uma feição mista e ademanes diferentes. Por outro lado, penetrando no tempo colonial, vamos achar uma sociedade diferente, e dos livros em que ela é tratada, alguns há de mérito real.

Num segundo momento, vêm as afirmações a respeito do gênero romance: 
Do romance de análise, raríssimo exemplar temos, ou porque a nossa índole não nos chame para aí, ou porque seja esta casta de obras ainda incompatível com a nossa adolescência literária.

Pelo que respeita à análise de paixões e caracteres são muito menos comuns os exemplos que podem satisfazer à crítica; alguns há, porém, de merecimento incontestável. Esta é, na verdade, uma das partes mais difíceis do romance, e ao mesmo tempo das mais superiores. Naturalmente exige da parte do escritor dotes não vulgares de observação, que, ainda em literaturas mais adiantadas, não andam a rodo nem são partilha do maior número.

Não é preciso enfatizar, creio: enquanto Machado mapeia a produção romanesca local, aponta, na sequência, para uma lacuna que considera de vulto: a quase ausência de romances de análise, a análise "de paixões e caracteres" em que, na sua produção romanesca, todos o sabemos, Machado iria justamente investir: seus romances pautam-se pelo confronto de caracteres.

Situação similar ocorre com o conto. Dele Machado afirma serem as tentativas raras, decorrentes, talvez, da natureza do próprio gênero:

É gênero difícil, a despeito de sua aparente facilidade, e creio que essa mesma aparência lhe faz mal, afastando-se dele os escritores, e não the dando, penso eu, o público toda a atenção de que ele é muitas vezes credor.

Considerando-se a extensa produção de contos ao longo de sua carreira como ficcionista - mais de duzentos -, pode-se afirmar que a lacuna entrevista por Machado, não obstante exercitasse o conto desde a década anterior, e, nesse sentido, pudesse, no ensaio, estar, no momento, a reivindicar a devida atenção a sua própria produção jornalística e ficcional, o levaria, em seu papel de ficcionista, ao longo da vida, a se transformar num exímio cultivador do gênero.

É por isso que afirmava, anteriormente: Machado mapeia a produção local, dialoga com ela, e, importante, percebe-lhe as lacunas, a serem virtualmente preenchidas com a sua 
atividade ficcional. Pega, em outras palavras, a tradição local, a vira e a revira pelo avesso, percebe-lhe as falhas "formativas", para saná-las. A isso se pode denominar empenho crítico, no sentido de rastrear e estudar a tradição, e de se preparar para nela intervir. Isso encontra-se já no "Instinto de nacionalidade".

Mas retomemos o fio da meada, deixando, por ora, essas questões nas sombras, embora fundamentais para o que viria a ser o Machado ficcionista, para divisar as suas posições diante das grandes linhas que orientavam a literatura de sua época. Afirmava, acima, que o autor, no "Instinto", exibia, como texto dominante, as posições românticas; ao negar, no entanto, o seu exclusivismo, preparava-se para a tarefa que se lhe antepunha: redirecionar a literatura brasileira para outros caminhos. Machado, em suma, assentado nessa dialética meio "ébria", que se agarrava na tradição romântica para deixar transparecer, sempre, assim como quem não quer nada, o "erro" e o acerto das posições vigentes à época, vislumbrava o futuro. O "Instinto", pode-se afirmar, é, nesse sentido, um texto analítico predominantemente marcado pelo Romantismo, coincidindo, em muito, com as posturas do que se convencionou, em termos da ficção machadiana, denominar de "primeira fase". A ruptura, no entanto, está lá, latente, como pretendi frisar acima.

\section{IV}

Os textos críticos posteriores - "O primo Basílio", de 1878, e "A nova geração", de 1879 - são textos que se situam já às portas de um Memórias póstumas de Brás Cubas e de um Quincas Borba. São páginas em que Machado critica ostensivamente o "Realismo" (Naturalismo) à Eça e Zola, ao mesmo tempo em que busca, e inaugura, como é possível percebê-lo nos romances da "segunda fase", uma nova ordem para o que pudesse significar "literatura brasileira" e a própria "nação".

O "Instinto" tem a ver com isso, pelo menos assim o imagino. É que Machado se apoiaria justamente na gangorra que instalara no "Instinto" para afastar-se do Romantismo e ir em busca de novas soluções narrativas, entrevistas nas afirmações contidas no que denominamos de subtexto que permeia o ensaio. Se com os ensaios críticos sobre Eça e o 
Realismo (Naturalismo) da "nova geração" Machado poderia enveredar para um beco sem saída, por não endossar, justamente, nem mais o Romantismo dos romances "fundacionais", nem a nova ordem predicada pelo Realismo/Naturalismo, assim como o entendia, era preciso criar uma solução que se estabelecesse como um outro subtexto por dentro do texto, um texto que carrega um outro em si, agora ficcional. É questão de método, analítico e poético.

Uma das principais saídas encontradas por Machado foi recorrer - sem esquecer, muito pelo contrário, o romance burguês clássico, canônico, de vertente francesa - à larga tradição "marginal" que se afirmara no norte europeu, relendo, entre outros, Laurence Sterne, com seu Tristram Shandy, ou os russos como Gogol, por exemplo, figura fundamental nesse processo de construção de um romance brasileiro que iria explorar, por detrás do texto aparente, ou do texto "realista" da tradição do romance "sério", a extravagância das situações, ou a tradição do "duplo" (Das Doppelgängermotiv), para, com isso, desvelar a realidade histórico-social do Brasil.

Não é o lugar de me deter, aqui, na análise do romance machadiano. A sua obra "madura", no entanto, se desdobra em romances em primeira pessoa e em terceira pessoa, em perfeito revezamento. Nos romances em primeira pessoa, como Memórias póstumas de Brás Cubas, a ênfase recai no universo particular, aparentemente individual, por trás do que se esconde o painel da sociedade local, com seus impasses, truculência e iniquidades. Por detrás da forma solta, enfim, surge a alegoria do social, que gradativamente toma conta do romance, a questionar a própria genealogia do nacional, como se lê no capítulo III do romance. Nos romances de voo largo, de sua parte, como Quincas Borba, por detrás da aparente forma canônica do romance real-naturalista surge o romance do disparate, da loucura, da negação não só da forma, mas da matéria nacional em seu viés ideológico corriqueiro.

Machado, poder-se-ia dizer, encontrou, assim, o seu caminho. Ele leu, releu, parodiou, no bom sentido, os seus predecessores brasileiros, como Manuel Antônio de Almeida, Macedo e Alencar. Leu os portugueses, "nossa" matriz cultural básica pela própria condição colonial, mas leu, também, Shakespeare, Sterne, Swift e Shelley, entre 
outros ingleses. Leu os moralistas franceses e os escritores pertencentes a uma tradição marginal na literatura do Ocidente, integrada por Luciano de Samósata e tantos outros, e leu os russos, como Gogol. Leiam-se Gogol e Dostoiévski, Gogol principalmente, com a representação dos funcionários subalternos, num Império estratificado, ou engessado pela burocracia, eles, os subalternos, vivendo de sopa de couve, com seus capotes rotos, a lembrar não somente alguns contos machadianos, mas também Quincas Borba, com a derrocada de Rubião. Leia-se, nesse sentido, o "Diário de um louco", com a sua linda Sofia, por quem o funcionário enlouquece de tanto amor, até vir a imaginar-se o rei da Espanha, e com os seus cães humanizados, que renderiam páginas pungentes, aliás, ao Quincas Borba, até pelo contraste entre o Quincas Borba cão e os "humanos" em geral, sem esquecer a empatia, entre irônica e elegíaca, com a loucura de Rubião, ou com o filósofo Quincas, como se pode ler nos capítulos XXVIII, XLIX, CLXXXVIII do romance... Leiam-se os russos, dizia, sob o impacto, eles, do final da servidão, equivalente, em termos relativos, à nossa abolição da escravidão, eles já na antevéspera do período revolucionário, enquanto, aqui, haveria de se instaurar a República. Por detrás das atitudes cotidianas, das sociabilidades formais, restar-nos-ia a loucura, equivalente da crítica radical da "nação".

Isso, acredito, importa ressaltar: o humour, a acidez meio mórbida que permeia o texto ficcional machadiano, pode ser a "salvação" do narrador, enquanto que a loucura, mesmo que com método, é a denúncia efetiva do que ia pelas entranhas da "nação". Na periferia da periferia do mundo dominado pelo capital, não havia espaço, enfim, só para comparar, nem para o romance "clássico" como representação do real, no sentido de Auerbach, nem, também, e isso é mero exemplo, para o romance que, diria, tenta pensar o pensamento, em busca de uma Bildung, como ocorrera com o romance do Idealismo alemão, também ele periférico, meio "fora do lugar" em relação ao cânone. Não. Restava, isto sim, a loucura como denúncia radical da inviabilidade da "nação".

Longe estamos, aqui, do "Instinto de nacionalidade", por certo, mas nem tanto. Se no artigo Machado colocava em relevo a tradição romântica sobre a nacionalidade, ele, ao mesmo tempo, através de seus meneios estilísticos típicos, entre a afirmação e o questionamento, método de pensamento e de escrita, preparava-se para superar essa mesma 
tradição. Conseguiu-o, diria, em seu campo de maior fôlego, o da ficção. Por isso mesmo é que se pode, decorridos 140 anos da publicação do "Instinto", colocar o artigo como um dos pontos altos da formação de Machado e da visão que constrói, gradativamente, sobre a "nação".

V

Isso, para não me deter, aqui, no rendimento do artigo para a historiografia literária brasileira, com Sílvio Romero, Zé Veríssimo e Antonio Candido, por exemplo. Com Sílvio, em sua constante diatribe com Machado, a incorporar, no entanto, o certo instinto de nacionalidade como régua de avaliação/julgamento das obras. Com Zé Veríssimo percorrendo a tradição literária local, assim como a vê, até chegar a Machado, em quem percebe o grande autor de uma literatura já formada. Com Candido escrevendo a Formação da literatura brasileira, incorporando os árcades ao patrimônio da literatura nacional, até chegar a Machado, ápice da formação literária brasileira. Ou, ficando ainda com Candido, ele a publicar "Literatura e subdesenvolvimento" justamente no centenário da publicação do "Instinto" (1973), quando revê, de maneira radical, a própria Formação, o "livro da ordem", ao destacar os impasses de nossa formação nacional, ou a anomia que atravessa a nossa história, em trajetória crítica que lembra não somente o "Instinto de nacionalidade", mas a trajetória do próprio Machado, desde o "Instinto", com a construção de uma tradição já minada pelo próprio estilo machadiano, até a sua radical crítica à nacionalidade, através da ficção...

\section{Referências:}

ASSIS, Machado de. Crítica literária. Rio de Janeiro;, São Paulo, Porto Alegre: W. M. Jackson Inc., 1955. 
Obra completa. Rio de Janeiro: Editora Nova Aguilar, 1997.

AUERBACH, Erich. Mimesis: a representação da realidade na literatura ocidental. São Paulo: Perspectiva, 1971.

CANDIDO, Antonio. Formação da literatura brasileira. São Paulo: Martins, 1964.

. A educação pela noite \& outros ensaios. São Paulo: Ática, 1987.

MORETTI, Franco. Atlas do romance europeu. 1800-1900. Tradução de Sandra Guardini Vasconcelos. São Paulo: Boitempo Editorial, 2003.

ROMERO, Sílvio. Machado de Assis - estudo comparativo de literatura brasileira. Campinas. São Paulo: Editora da Unicamp, 1992.

ROMERO, Sílvio. História da literatura brasileira. Rio de Janeiro: José Olympio, 1960.

SÁ REGO, Enylton José de. O calandu e a panaceia: Machado de Assis, a sátira menipeia e a tradição luciânica. Rio de Janeiro: Forense Universitária, 1989.

SCHWARZ, Roberto. Ao vencedor as batatas. São Paulo: Duas Cidades, 1977.

. Um mestre na periferia do capitalismo: Machado de Assis. São Paulo: Duas Cidades, 1990.

STERNE, Laurence. A vida e as opiniões do cavalheiro Tristram Shandy. Tradução, introdução e notas por José Paulo Paes. São Paulo: Companhia das Letras, 1998.

SILVA, Ana Cláudia Suriani da. Gogol, matriz de Quincas Borba. In: Machado de Assis em linha, n. 1, junho de 2008. Acessível em: <http://machadodeassis.net/download /numero01/num01 artigo08.pdf>. Acesso em: 10.11.2013.

VERÍSSIMO, José. História da literatura brasileira. Rio de Janeiro, José Olympio, 1969.

WEBER, João Hernesto. A nação e o paraíso: a construção da nacionalidade na historiografia literária brasileira. Florianópolis: EdUFSC, 1998.

. Tradição literária \& tradição crítica. Porto Alegre: Movimento, 2009.

. Machado de Assis - uma apresentação. Porto Alegre: Movimento, 2013.

João Hernesto Weber é licenciado em Letras pela UFRGS, onde realizou seu mestrado e doutorado. Foi professor de Literatura Brasileira na Universidade Federal de Santa Catarina. É autor de Do Modernismo à Nova Narrativa (Porto Alegre: IEL/Metrópole, 1976), Caminhos do romance brasileiro - de A Moreninha a Os Guaianãs (Porto Alegre: Mercado Aberto, 1990), A Nação e o Paraíso (Florianópolis: EdUFSC, 1998), Tradição literária \& Tradição crítica (Porto Alegre: Movimento, 2009), Machado de Assis - uma apresentação (Porto Alegre: Movimento, 2013), além de vários capítulos de livro e artigos em revistas e jornais da área de Literatura e História. E-mail: <weberjh@gmail.com>. 